\title{
A Case report on Midline Facial Cleft Associated with Ambiguous
} Genitalia and Umbilical Defect

\author{
H. A. Amaratunga ${ }^{1}$, S. P. M. Peiris ${ }^{2}$, A. G. G. Wijerathne ${ }^{1}$, J. K. Dissanayake ${ }^{1}$
}

\begin{abstract}
Congenital midline facial anomalies are a rare group of disorders that are often accompanied by a constellation of other clinical anomalies, many of which have been recognized as syndromes. The index case is a child with midline facial defect with cleft palate associated with ambiguous genitalia and an umbilical defect. Differential diagnoses including Holoprocencephaly (HPE), Midline facial Plane defect, Oral-facial Digital syndrome, and Kallmanns syndrome are discussed. Although the most probable diagnosis is HPE, ambiguous genitalia and umbilical deformity are atypical findings which merit special mention.
\end{abstract}

Key words: Midline facial cleft, ambiguous genitalia, cleft lip and palate

\section{INTRODUCTION}

Although orofacial defects are among the most common of congenital deformities, arising in 1 in 700 live births (1). Midline facial defects are rare. Whilst early diagnosis and well-timed surgical interventions are mandatory for a normal life, management is often imperfect, due to the fact that syndromic associations are difficult to define. Among the associations reported in the literature, conditions such as holoprocencephaly, oro-facial-digital syndrome, Median Facial Plane defect and Kallmanns syndrome require consideration. We report a case of midline facial defect, associated with ambiguous genitalia and umbilical hernia.

\section{CASE REPORT}

Informed consent was sort from the parents for publication of this material. The proband is a month old baby, born at 40 weeks gestation, with a birth weight of 2500grams, being the third child of a consanguineous marriage. Examination revealed a mid-line facial cleft separating the upper lip and a complete palatal cleft and microcephaly (Figure1).

An umbilical hernia and an underdeveloped phallus with incomplete labial separation and no obvious vaginal opening were also detected (Figure 2). An ovoid mass was palpable in the left labioscrotal fold. Other systems were normal.

A trans-fontanellar ultrasound scan of the 
H. A. Amaratunga, S. P. M. Peiris, A. G. G. Wijerathne, J. K. Dissanayake. A Case Report on Midline Facial Cleft Associated with Ambiguous Genitalia and Umbilical Defect. Sri Lanka Anatomy Journal (SLAJ), 1(1):60-63, 2017.

brain confirmed microcephaly. Abdominal ultrasound scan identified the inguinal mass as the left testis. The right testis, ovaries or a uterus could not be detected. Following on a presumptive diagnosis of Kallmanns' Syndrome, thyroid hormones, TSH levels and HCG levels were investigated in order to assess pituitary functions. The results were normal. At the age of 1 month the baby was referred to the Department of Maxillofacial Surgery, Faculty of Dental Sciences, Peradeniya, Sri Lanka for further management. An additional referral was also made to the Department of Anatomy, University of Peradeniya for further assessment of ambiguous genitalia. A buccal smear preparation for the identification of $\mathrm{X}$ chromatin was carried out but was found to be negative favoring that of the male genotype. Follow-up revealed that although the weight gain was steady, the occipito-frontal circumference was not increasing to expected standards.

An operative corrective procedure was performed on the external facial defect under general anaesthesia by the consultant maxillofacial surgeon. No intraoperative complications were noted, but due to the atresia of the nasal segment postoperative intranasal intubation was required. The immediate postoperative course was uneventful. Feeding was commenced 4 hours later and recovery henceforth was expedient. The nares were extubated two days later and normal respiration was established.
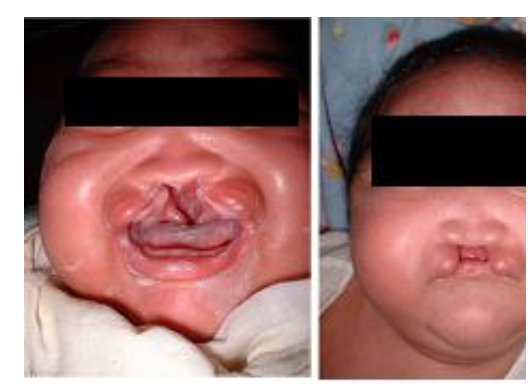

Figure 1. Midline facial cleft extending into a palatal cleft

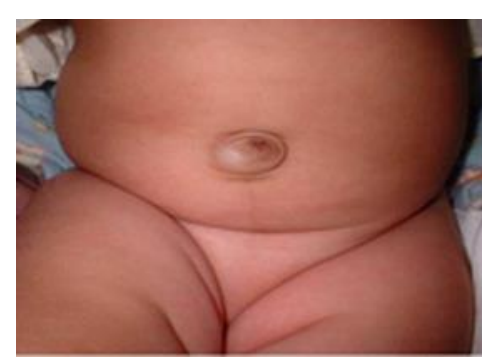

Figure 2. Umbillical hernia

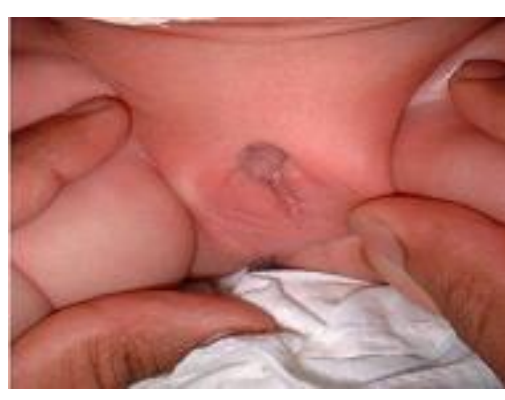

Figure 3. Appearance of genitalia 
H. A. Amaratunga, S. P. M. Peiris, A. G. G. Wijerathne, J. K. Dissanayake. A Case Report on Midline Facial Cleft Associated with Ambiguous Genitalia and Umbilical Defect. Sri Lanka Anatomy Journal (SLAJ), 1(1):60-63, 2017.

\section{DISCUSSION}

Cleft lip with or without associated cleft palate (CLP) is one of the most common congenital anomalies accounting for 9.92 per 10,000 live births worldwide.(2) However, median cleft lip, is very rare and accounts for only about $0.5 \%$ of all cases of cleft lip (2).

A median cleft lip is one that involves the middle of the upper lip the area of the philtrum. This defect has a different pathophysiology from CLP and is caused by a lack of development of the maxillary bony processes to extend medially and join in the midline below the nose (3). This median cleft lip anomaly has been associated with several disorders, which are holoprosencephaly (a severe anomaly of the brain), Oral-Facial-Digital (OFD) syndrome and Median Facial Plane (MFP) defect. MFP is a defect that involves the eyes, nose, and forehead. Major features of this abnormality include hypertelorism, a bifid nose, and a broad nasal bridge in association with a median cleft lip and palate. In the index case, however, the hyperteleorism index was 3.35, falling well within the normal (4). Furthermore, the nose was not bifid, and no evidence of frontal encephalocele could be found. Holoprocencephaly is accompanied by a spectrum of characteristic craniofacial anomalies in about $80 \%$ of patients (5). Malformations of the nose include complete absence, agenesis of the nasal cartridge, and proboscis (flat nose with a single central nostril without nasal bones), and palatal anomalies include midline and lateral clefts, midline palatal ridge, bifid uvula and absence of the superior labial frenulum, all of which are consistent with the proband. However, in addition to the above, the proband also has an umbilical hernia and ambiguous genitalia, not commonly described in association with holoprocencephaly.

The presumptive diagnosis of Kallmann de Morsier Syndrome refers to the association of congenital hypogonadotropichypogonadism with anosmia or hyposmia. Although it is associated with midline facial defects, other manifestations such as syndactily, short forth metacarpals, craniofacial asymmetry, renal agenesis, nerve deafness, malrotation of the gut, congenital heart disease were not in evidence.

\section{CONCLUSION}

Median cleft lip and palate is a rare condition and maybe associated with different congenital anomalies. Such cases warrant mention due to difficulties in management of these patients. 


\section{REFERENCES}

1. Mossey P, Castilla E. Global registry and database on craniofacial anomalies: report of a WHO Registry Meeting on Craniofacial anomalies: Geneva, Switzerland: 2001.

http://www.who.int/genomics/anomalies/e n/CFA-RegistryMeeting-2001.pdf

2. Sekhon PS, Ethunandan M, Markus AF, Krishnan G, Rao CB. Congenital anomalies associated with cleft lip and palate-an analysis of 1623 consecutive patients. Cleft Palate-craniofacial J, 2011;48:371-8.

3. Sedano HO, Gorlin RJ. Frontonasal malformation as a field defect and in syndromic associations. Oral Sur Oral Med Oral Pathol 1988;65:704-10.

4. Evereklioglu C, Doganay S, Er H, Tercan M, Gunduz A, Balat A, Borasan M. Interpupillary index: a new parameter for hypo-hypertelorism. JCraniomaxillofac Surg2001;29:191-4.

5. DeMyer W. The median cleft face syndrome. Differential diagnosis of cranium bifidum occultum, hypertelorism, and median cleft nose, lip, and palate. Neurol. 1967;17:961-71.

\section{CORRESPONDENCE:}

Dr. H. A. Amaratunga,

Department of Anatomy, Faculty of Medicine,

University of Peradeniya,

Sri Lanka,

Email-himanip@pdn.ac.lk,

Received: July 2017

Accepted: August 2017 